\title{
Cruzando fronteiras: as obras e o legado de Freire na Itália
}

Silvia Maria Manfredi

Professora livre-docente aposentada da Faculdade de Educação da Unicamp

e presidente do Instituto Paulo Freire - Itália.

E-mail: silmanf@hotmail.com

Resumo: Este artigo recupera e analisa momentos do exílio de Paulo Freire na Europa. Neste período (1970-1980), as obras de Freire começaram a ser traduzidas e conhecidas em diferentes países do velho continente, conquistando especialmente o público italiano. A difusão das obras de Freire na Itália pode ser identificada em dois períodos históricos distintos: o primeiro sendo os anos 1960 e 1970, em que os temas e as experiências desenvolvidas por Freire no Brasil e na América Latina se ligam ao contexto das lutas e das experiências emancipatórias dos movimentos sociais e culturais italianos durante o contexto de reconstrução econômica, social e política pós-Segunda Guerra Mundial. Já o segundo se dá em 2005 com a criação do Instituto Paulo Freire Itália, que assume o papel de levar adiante a tarefa de custodiar, difundir e reinventar o legado do educador.

Palavras-chave: Freire no exílio; pedagogia freiriana na Itália; IPF Itália; fóruns e rede internacional.
Abstract: The article recovers and analyzes moments of Paulo Freire's exile in Europe. During this period (1970-1980), Freire's works started being translated and known in different countries of the old continent, conquering the Italian public especially. We can identify two distinct historical periods of the diffusion of Freire's works in Italy: the first in the 1960s and 1970s, in which the themes and experiences developed by Freire in Brazil and in Latin America are linked to the context of the struggles and emancipatory experiences of Italian social and cultural movements in the context of economic, social, and political reconstruction post-World War II. The second happens in 2005, with the creation of the Instituto Paulo Freire-Italia, this association, which assumes the role of carrying out the task of guarding, diffusing, and reinventing the educator's legacy.

Keywords: Freire in exile; freirian pedagogy in Italy; IPF Italy; forums and international network. 
comunicação \& educação • Ano XXVI • número 2 • jul/dez 2021

\section{INTRODUÇÃO}

O exílio político que impediu Paulo Freire de continuar sua obra no Brasil, após o sucesso da Campanha de Alfabetização de Angicos e do Programa Nacional de Alfabetização de 1964, deu-lhe, paradoxalmente, a oportunidade para difundir suas experiências e escritos para além das fronteiras geográficas brasileiras. Interditado em seu país, o exílio escancarou-lhe as portas para o ingresso em outros continentes. Vivendo e atuando em outros países da América Latina, América do Norte, Europa e África, Freire pôde difundir seus escritos, construir novas propostas e dialogar com expoentes de vários campos do conhecimento. Enfim, pôde se enriquecer pessoal e profissionalmente. Desta forma, tornou-se, no decorrer das últimas décadas do século XX, o filósofo e pedagogista mais lido e conhecido nas grandes universidades e instituições educacionais de países de vários continentes. Conhecido como um pensador crítico a favor das classes oprimidas, foi referência teórico-prática para muitos grupos e entidades envolvidos com projetos educativos para a transformação educacional, fossem eles de cunho inovador ou revolucionário. Como andarilho da esperança e defensor de uma filosofia educativa para a construção de direitos, da liberdade e da democracia, tendo grande poder de transformar pessoas em sujeitos agentes de mudanças nas sociedades, inspirou indivíduos e grupos de diversos matizes político-ideológicos. Foi e continua sendo um filósofo e educador conhecido mundialmente como defensor de processos de inclusão, de democratização e de luta por direitos sociais e políticos.

A maior parte de suas obras foram disseminadas no mundo acadêmico através de interlocutores e intelectuais pertencentes às mais variadas áreas do conhecimento, em ciências humanas e exatas. Não raro se encontrava com intelectuais eminentes para conversar, trocar ideias, debater e confrontar visões epistemológicas e orientações teóricas próximas ou distintas. Penso que tal abertura pessoal e intelectual, típica de quem fazia do diálogo um princípio irrenunciável na produção de conhecimento, tenham enriquecido Freire como pessoa e, consequentemente, auxiliado seus escritos e suas experiências a alcançarem reconhecimento e prestígio mundo afora. Além do diálogo, Paulo Freire privilegiava o trabalho em equipe, seu modus operandi preferido, pois assim podia construir com outros intelectuais percursos de pesquisa, de intervenção e de publicação de livros. Alguns exemplos disso são o Instituto de Ação Cultural (Idac), na Suíça, e o Instituto Paulo Freire em São Paulo (IPF-SP) ${ }^{1}$.

1. O Idac é um centro de pesquisa e intervenção pedagógica criado por Freire e um grupo de intelectuais brasileiros durante o exílio do educador, constituído em 1970, em Genebra. Fizeram parte do Idac: Miguel Rosiska, Darcy de Oliveira, Darcy de Oliveira e Claudius Ceccon. O IPF, em São Paulo, foi oficializado em abril de 1991.

\section{PAULO FREIRE ATERRISSA NA EUROPA}

Depois de alguns anos de exílio, passando primeiro pela Bolívia, Chile, México e Estados Unidos, a partir de fevereiro de 1970, Paulo Freire assume residência em Genebra, Suíça, e inicia um trabalho junto ao Conselho Mundial de Igrejas (CMI) até junho de 1980. Tendo sido também professor da Universidade 
de Genebra, Freire desenvolveu experiências em diferentes países não só europeus, mas também africanos.

Sem dúvida alguma, a porta de entrada de Freire na Europa foi a tradução de sua obra Pedagogia do oprimido. Como registra Gadotti ${ }^{2}$, Pedagogia do oprimido foi o livro que mais teve edições, sendo que neste período, na Europa, a obra chegou na Itália e em Portugal, em 1971, no Reino Unido e na Holanda em 1972, na França e na Grécia em 1974, na Espanha em 1978 e na Alemanha em 1979. Gadotti ainda faz referência à existência de traduções deste livro em sueco, norueguês, finlandês, dinamarquês e flamengo ${ }^{3}$.

A tradução da Pedagogia do oprimido nas diferentes línguas europeias repercutiu em dois tipos de leitores: "[...] de um lado, junto a educadores descontentes e desencantados com a escola e, de outro, junto a grupos sociais em movimento que tentavam construir contextos educativos, capazes de produzir conhecimentos e valores novos"4.

Na década de 1970, crescia na Europa o interesse e a identificação das pessoas com as experiências latino-americanas, de modo que intelectuais exilados eram convidados para participarem de encontros e seminários para um confronto crítico de experiências e vivências expressas e teorizadas na Pedagogia do oprimido. Assim nasceu, em 1970, o Idac.

Sendo Genebra a sede do Idac, Freire e demais brasileiros receberam convites de grupos interessados em aprofundar temas ligados à alfabetização e à educação de adultos, à reinvenção da escola e às pedagogias libertadoras. Não raro eram convidados para assessorar a elaboração de novos projetos de educação para os nascentes movimentos sociais dos anos 1970 e para participar de encontros, seminários e conferências em vários países europeus, de norte a sul. Posteriormente, nos anos 1980, Freire assessorou programas de alfabetização junto aos movimentos de descolonização africanos de língua portuguesa. Há referências e documentos que atestam a colaboração do Idac em vários países ao mesmo tempo que as obras de Freire passam a ser lidas e utilizadas em vários departamentos e faculdades de educação das principais universidades europeias.

No livro Vivendo e aprendend $o^{5}$, Freire, Rosiska, Oliveira e Ceccon relatam três das experiências vividas pelo Idac: (1) o envolvimento no projeto das 150 horas junto ao movimento sindical italiano de 1972 a 1974; (2) a experiência de educação com mulheres no âmbito do movimento feminista da Suíça, de 1973; (3) a experiência de reconstrução da escola, da alfabetização e da educação de adultos na Guiné-Bissau de 1976 a $1979^{6}$.

Neste artigo, daremos destaque à participação do Idac no projeto das 150 horas e no movimento operário sindical italiano.

\section{PAULO FREIRE NA ITÁLIA}

A difusão das obras de Freire na Itália pode ser diferenciada em duas fases. A primeira é relativa aos anos 1960 e 1970, em que os temas e as experiências
2. GADOTTI, Moacir. The global impact of Freire's pedagogy. New directions of evaluation, London, v. 2017, n. 155, p. $17-30,2017$.

3. Gadotti refere, em 1996, apenas sobre Pedagogia do oprimido, 27 edições publicadas em diferentes línguas.

4. FREIRE, Paulo; ROSISKA, Miguel; OLIVEIRA, Darcy de; CECCON, Claudius. Vivendo e aprendendo: experiências do Idac em educação popular. 4. ed. São Paulo: Brasiliense, 1981, p. 11.

5. Ibidem.

6. Paulo Freire participou de outros projetos de alfabetização de adultos na África; visitou a Zâmbia, a Tanzânia, a Guiné-Bissau, São Tomé e Príncipe, Angola e Cabo Verde. Reuniu-se com o Movimento Popular de Libertação da Angola (MPLA), a Frente de Libertação de Moçambique (Frelimo) e o Partido Africano para a Independência da Guiné e Cabo Verde (PAIGC), além de ter desenvolvido programas de alfabetização de adultos na Guiné-Bissau, na Tanzânia e em Angola. Freire lia bastante acerca da colonização e os seus efeitos sociais, incluindo os escritos de revolucionários e intelectuais como o caribenho Frantz Fanon e o africano Amílcar Cabral. 
desenvolvidas por Freire no Brasil e na América Latina se ligam ao contexto das lutas e das experiências emancipatórias dos movimentos sociais e culturais italianos desse período. A segunda fase, após um interregno de quase 20 anos, num outro contexto histórico, refere-se à virada dos anos 2000.

Freire passou a ser conhecido na Europa não apenas pela Pedagogia do oprimido, mas também pelo livro Educação como prática da liberdade. Ambas as obras foram traduzidas para o italiano, respectivamente, em 1971 e 1973, pela editora Mondadori. A primeira edição da Pedagogia do oprimido contou com apresentação do próprio Freire? ${ }^{7}$

\subsection{A descoberta das obras de Freire}

Durante os anos 1960 e 1970, a Europa vivia os efeitos da Guerra Fria e os desafios da superação das ruínas deixadas pela Segunda Guerra Mundial, enfrentando graves problemas de desemprego e inflação e trabalhando a retomada do crescimento econômico. A Itália enfrentava o desafio da reconstrução de seu parque industrial, cujos problemas eram decorrentes de fortes processos de migração interna - do sul para o norte -, bem como da reconstrução dos centros urbanos - habitação, transporte, infraestrutura etc. - e do enfrentamento da pobreza e das desigualdades imperantes nas regiões menos desenvolvidas do mezzogiorno, isto é, do centro-sul.

Do ponto de vista político, o processo de democratização do Estado e da sociedade civil seguia um percurso cheio de contradições e disputas ideológicas, além de estar permeado por resquícios e marcas deixados pela ditadura fascista e pelo questionamento dos regimes ditatoriais - Espanha, Portugal e Grécia e da expansão do colonialismo nos países do continente africano. Persistia na Itália um clima social e político de politização dos problemas ligados à vida cotidiana que impulsionou reivindicações e lutas pela democratização e ampliação de oportunidades em todos os campos e setores, notadamente no âmbito dos direitos civis, trabalhistas e educacionais. Além disso, demandava-se o acesso à cultura e à participação política. Ventos da contestação agitavam e animavam as novas gerações de trabalhadores nos sindicatos, como mulheres e estudantes. Daí os contrastes e conflitos com os valores e os modelos político-ideológicos conservadores dominantes. Nesse contexto histórico, em que imperava um clima de lutas e renascimento dos movimentos sociais, "a proposta freiriana foi acolhida e entendida como terzomondista, militante e revolucionária”.

A abordagem político-educativa desenvolvida por Freire na Pedagogia do

oprimido estava em sintonia com as reivindicações e energias de transformação político-cultural do movimento operário sindical e dos grupos que denunciavam a escola pelo seu caráter elitista. No debate público, as representações e as manifestações da cultura dominante eram desveladas, colocadas em xeque e contrapostas com os discursos de valorização da cultura dos oprimidos e das culturas subalternas, na expressão gramsciana. No âmbito pedagógico, 
o confronto com a visão elitista de cultura e educação originou experiências alternativas no campo da educação e da cultura popular.

O ativismo e a participação social e política extrapolam, por fim, os confins tradicionais da família e da escola e invadem igrejas, associações de bairro e sindicatos por meio de experiências educativas informais e espontâneas, muitas vezes em contraste com a educação escolar. Nascem durante essa época novas experiências de educação popular de adultos - com trabalhadores(as), mulheres, idosos e grupos de vizinhança - e de grupos de desenvolvimento comunitário. Assim, estava em curso uma nova perspectiva de educação popular na Itália, que transitava de uma sociedade agrícola para uma industrial num contexto de reconstrução pós-guerra9 ${ }^{9}$.

São os militantes e os educadores populares, protagonistas dos movimentos sociais urbanos, que se apropriam das obras de Freire ${ }^{10}$. Alguns destes sujeitos eram vinculados a iniciativas de setores da Ação Católica Italiana (ACR) - na maioria, grupos de pastorais, em dioceses capitaneadas por religiosos progressistas - simpatizantes com a teologia da libertação e orientados pela "opção preferencial pelos pobres"11 emanada no Concílio Vaticano II.

Nesse circuito de práticas, cabe mencionar a experiência de Gino Piccio, sacerdote da diocese de Casale Monferrato, que, depois de ter lido a Pedagogia do oprimido, ficou entusiasmado e foi ao encontro de Freire em Genebra. Passou, assim, a projetar e a realizar ações educativas com camponeses adultos, seguindo fielmente a proposta de Freire em Educação como prática para a liberdade. Além de Monferrato, também fez trabalhos educativos em Friuli-Venezia Giulia e em Irpinia por ocasião dos terremotos que devastaram essas regiões italianas. Quando se estabeleceu definitivamente no município de Ottiglio, na província de Alexandria, criou um centro de formação - La Cascina $G$ - onde promovia atividades de formação para jovens, educadores, professores e trabalhadores sociais, sempre tendo como paradigma a pedagogia freiriana. Ademais, foi um dos sócios fundadores do IPF Itália e, mesmo falecido, suas atividades de formação continuam sendo promovidas através de um de seus seguidores, que difunde o projeto de Don Piccio, cuja referência continua sendo Paulo Freire ${ }^{12}$.

\subsection{O Idac e o movimento sindical italiano: a luta pelo direito ao estudo e o projeto das 150 horas}

Este projeto educativo nasce no interior de setores do movimento operário sindical italiano que, em seu percurso de lutas e reivindicações, exige o direito ao estudo e o acesso à cultura, estes sendo os principais pontos de sua agenda de lutas. Assim, foram os "próprios sindicatos que se constituíram no sujeito coletivo responsável pela concepção e execução da experiência"13.

Tal projeto educativo nasce da tomada de consciência de que a maior parte dos trabalhadores não tinha tido a oportunidade de completar o primeiro ciclo da escolaridade básica - na Itália, scuola dell'obbligo ${ }^{14}$ - e da vontade política
9. Ibidem.

10. Testemunhos, apropriações e comentários feitos por intelectuais italianos na década de 1970 podem ser encontrados em: BELLANOVA, Bartolomeo. Paulo Freire: educazione problematizzante e prassi sociale per la liberazione - contesti antologici di e sull'autoreappendicesu documentied esperienze. San Prospero: Modena, 1978.

11. NANNI, Carlo. Teoria.. Op. cit., p. 96.

12. O seguidor de Piccio criou uma associação específica para a formação de educadores, animadores sociais e professores. Mais informações podem ser obtidas em: www.studiokappa.it.

13. FREIRE, Paulo; ROSISKA, Miguel; OLIVEIRA, Darcy de; CECCON, Claudius. Vivendo... Op. cit., p. 16.

14. Na época, quase $70 \%$ dos trabalhadores das regiões do norte do país e mais de $80 \%$ nas regiões meridionais tinham completado a escolaridade obrigatória de oito anos da época - 11 anos atualmente. Projeto semelhante foi organizado e desenvolvido no Brasil durante os anos 1990, denominado Integrar, por iniciativa da Confederação Nacional dos Metalúrgicos da Central Única dos Trabalhadores (CNM-CUT). Ver, a esse respeito: MANFREDI, Silvia Maria. Educação profissional no Brasil: atores e cenários ao longo da história. Jundiaí: Paco, 2016. 
de formar líderes operários e dirigentes para atuarem nas lutas no interior das fábricas e como ativistas no âmbito da sociedade civil. O significado dessa batalha político-pedagógica, segundo um historiador italiano,

[...] emerge não somente da necessidade de atualização e formação cultural dos trabalhadores, mas da vontade política de transformar a realidade das fábricas e da classe trabalhadora, não mais disposta a ser considerada simples força de trabalho e de produção de mercadorias, mas determinada a construir uma identidade política e cultural própria ${ }^{15}$.

As grandes lutas operárias dos anos 1960 e 1970, na Itália, pautaram-se em torno de questões e reivindicações qualitativamente diferentes e mais amplas que as melhorias salariais e a defesa do posto de trabalho. As reivindicações também eram relativas à organização do processo do trabalho, da gestão e do poder dos patrões no interior das fábricas. As grandes greves do norte da Itália, no final da década de 1960 e em boa parte da década de 1970, pautaram o direito dos operários de controlarem os horários e ritmos do trabalho e o direito a boas condições de trabalho, passando a exigir o controle dos meios de produção que incidem sobre a saúde, como o barulho, emanações tóxicas, calor, exaustão devido às horas extras e ao trabalho noturno etc. ${ }^{15}$.

O combate pelo controle das condições de trabalho, se articula com um grupo de reivindicações, definidas como o de poder e liberdade, tais como o direito à constituição de conselhos de fábrica como forma de enraizar o assemble sindicato nas bases operarias, de promover assembleias dentro das fabricas, o acesso à informação dos planos patronais de reestruturação da produção, programas de investimentos, rotatividade e formação da mão de obra ${ }^{16}$.

O movimento sindical italiano, como o novo sindicalismo no Brasil, na década de 1990, percebe que as contradições vivenciadas no interior das fábricas se alastram para a sociedade civil. Nesse sentido, verifica-se a importância de vincular a luta com o território para que ela também possa atuar em outras frentes: na preservação do meio ambiente, nas lutas no âmbito dos transportes coletivos, no acesso à moradia, ao descanso e ao lazer, mas, especialmente, no direito ao estudo e à cultura.

Na esteira desta última frente, a Federação dos Metalúrgicos inclui no contrato nacional de 1973 o direito ao estudo, que deu origem ao projeto das 150 horas. O projeto significava o direito de cada trabalhador utilizar 150

15. VITTORIA, Paolo. Paulo Freire e l'educazione degli operai in Italia. Alternative - rivista per il socialismo, Roma, p. 1-10, 2007, p. 2.

16. FREIRE, Paulo; ROSISKA, Miguel; OLIVEIRA, Darcy de; CECCON, Claudius. Vivendo... Op. cit.

17. Ibidem, p. 18.

18. Ibidem, p. 19 horas, deduzidas do tempo de trabalho e remuneradas pelos patrões, para sua formação durante três anos ${ }^{18}$.

Nesse contexto, representantes do movimento operário sindical, tomando como referência o livro Pedagogia do oprimido, entraram em contato com o Idac. Resultaram desse contato uma série de seminários e, em 1973, a participação da equipe do Idac no planejamento e na execução de uma experiência renovadora de educação de adultos trabalhadores.

Assim, a reivindicação do direto ao estudo possuía três objetivos principais: 
a. Acesso à educação de nível básico e fundamental com a possibilidade de possuir uma certificação educacional e profissional de modo a corrigir as discriminações de acesso e de inserção no mercado de trabalho;

b. Aquisição de conhecimentos e instrumentos para qualificar as lutas dos trabalhadores nas lutas e negociações feitas coletivamente dentro (nos conselhos de fábrica) e fora das fabricas;

c. Questionar e possibilitar a construção de formas alternativas de educação escolar, forçando a escola pública a repensar objetivos, conteúdos, métodos e políticas de escolarização ${ }^{19}$.

Inicialmente, a proposta encontrou obstáculos de ordem político institucional tanto por parte do patronato, cuja expectativa de formação era focada estritamente na qualificação profissional, quanto por parte do Ministério da Educação. Mas, considerando a força de mobilização social e política do movimento operário sindical do período, a proposta saiu vencedora.

Quanto ao locus de execução do programa, escolheu-se a escola pública, de modo a evitar que o projeto das 150 horas se "transformasse numa experiência alternativa e marginal ao sistema de ensino oficial, como uma escola de segunda mão para os operários" ${ }^{20}$. Os professores das escolas foram desafiados a atuarem não só como educadores, mas também em parceria com os trabalhadores, redefinindo-se, assim, o papel dos educadores e o modelo da escola tradicional, agora pautados nos princípios freirianos de diálogo, troca de saberes, participação e produção coletiva por meio do planejamento, da execução e da avaliação conjunta. Os cursos foram realizados em escolas públicas e com professores remunerados pelo Estado. O ensino foi gratuito e os programas foram estabelecidos com a participação dos trabalhadores.

Assim, todo o verão de 1973 foi atravessado por debates entre sindicalistas, educadores e intelectuais que visavam definir as linhas mestras do programa, discutindo os objetivos, os conteúdos e os métodos que seriam adotados. Discutiam também questões relativas às expectativas, às vivências das experiências pregressas dos trabalhadores, ao aporte de saberes diferentes, à relação entre a cultura popular e a cultura da escola, à valorização do saber por experiência, à articulação do saber e da cultura popular com o conhecimento sistematizado das diversas áreas do conhecimento... Enfim, questões que geralmente são colocadas quando se busca uma proposta político-pedagógica de educação popular com o intuito de conhecer para transformar ${ }^{21}$.

Depois de inúmeros debates e confrontos, chegou-se a uma proposta didático-metodológica que adotava fases comuns a todos os grupos de operários que se organizaram nas escolas.

A primeira fase se tratava da explicitação dos objetivos do projeto, em que, por meio de assembleias paritárias, os participantes - trabalhadores, dirigentes sindicais, professores responsáveis pelos cursos e outros pertencentes dos escolares - se reuniram para apresentar e discutir o projeto das 150 horas, que

19. Ibidem, p. 24. 20. Ibidem, p. 20 21. Ibidem, p. 23. 
significava a conquista do direito ao estudo e a volta à escola a partir de uma nova concepção político-educativa.

A segunda fase consistia no trabalho organizado em pequenos grupos, envolvendo apenas professores e trabalhadores. Tomava-se como ponto de partida a narrativa individual de cada trabalhador, em que sua história e suas expectativas em relação ao curso eram expostas. Os dados recolhidos eram sistematizados numa síntese global. A análise e a discussão da síntese marcavam a passagem das histórias singulares de vida e de trabalho de cada um para a dimensão coletiva, realçando, dessa forma, os principais problemas que afetavam a todos, sendo, portanto, comuns. Passava-se, então, ao debate desses problemas, extraindo os temas que o grupo aprofundaria e pesquisaria. Em linguagem freiriana, os temas geradores e os subtemas podiam ser aprofundados tanto por uma perspectiva interdisciplinar quanto por uma de enriquecimento de capacidades cognitivas de comunicação verbal e escrita e, ainda, político-organizativas. Uma vez escolhidos os temas e subtemas, iniciava-se a terceira etapa - o aprofundamento através de um itinerário de pesquisa realizado em subgrupos.

Os itinerários que guiariam o aprofundamento da terceira etapa podiam envolver a participação de especialistas externos à escola, como economistas, historiadores, sindicalistas, juristas etc., bem como o uso de procedimentos e materiais didáticos pouco utilizados nas escolas, por exemplo, a condução e a gravação de entrevistas ou o uso de fontes de informação diversas - jornais, revistas, material estatístico, fotos, música etc. Os principais temas geradores se referiam a questões ligadas ao trabalho nas fábricas - funcionamento e organização do trabalho capitalista, ambiente de vida e de trabalho e sua relação com a saúde física e mental -, à sociedade e ao meio ambiente, à relação entre campo e cidade, industrialização e urbanização e trabalhadores e Estado, à relação com o poder - como funciona o sistema político e o sistema jurídico atual e na história -, à informação e à cultura - diferentes meios e formas de comunicação e formas de cultura.

Já a quarta etapa consistia na apresentação dos trabalhos e na elaboração de um relatório final que sistematizasse os conteúdos desenvolvidos, a contribuição individual de cada participante e de cada subgrupo e incluísse os textos e materiais utilizados e produzidos. Basicamente, era necessário sistematizar as questões abordadas, o processo, os materiais utilizados e os resultados obtidos.

A experiência histórica das 150 horas foi muito significativa, visto que atingiu milhares de trabalhadores e, com o passar dos anos, sofreu modificações à medida que outras categorias de trabalhadores passaram a reivindicar e a conquistar o direito ao estudo e à cultura. O projeto perdeu sua força e intenção sociocultural e política em função das mudanças econômicas, sociais e políticas que ocorreram na Itália no final dos anos 1970 e 1980, que transformaram as estratégias de atuação dos sindicatos frente aos novos processos e crises socioeconômicas e políticas geradas pela globalização da economia europeia.

Os primeiros anos de realização da experiência de 150 horas caracterizaram-se por uma forte ligação política. As 150 horas representaram o fruto de uma conquista social do Movimento dos Metalúrgicos: isso marcou a história dessa singular 
experiência político-educacional em seus primeiros anos de vida. A partir de 75/76, a reivindicação das 150 horas foi estendida a outras de categorias sociais que não tinham história e consciência política como a dos operários: comerciantes, donas de casa, agricultores, desempregados. Se, por um lado, a extensão de 150 horas a outras categorias de trabalhadores e trabalhadoras significou a difusão de uma conquista social e, portanto, sua democratização - por outro, distorceu as características da consciência política e da transformação cultural que tinha sofrido, inicialmente graças ao impulso dos metalúrgicos, não é por acaso que, referindo-se às 150 horas, se utiliza a palavra experiência. Ao usar este termo no contexto histórico, presume-se que houve um começo e um fim. De fato, as 150 horas tornaram-se um direito adquirido, mas a experiência permaneceu singular com o emblema de uma educação alternativa... nos dias atuais a lei 53/2000, garante a trabalhadores/ as o direito de se ausentar do trabalho para participar de atividades de formação permanente. Diferencia-se das 150 horas porque a formação é focada nos interesses das empresas e demandada a partir de solicitações individuais, ainda que seja estabelecida a partir das normas dos contratos coletivos de trabalho. A educação de adultos, hoje na Europa e Itália, rebatizada com o título de long life learning, educação permanente, não possui a mesma concepção nem a mesma conotação política. Permanece no âmbito das orientações neoliberais, no âmbito de acúmulo de novos conhecimentos, atualização individual ${ }^{22}$.

No que diz respeito ao propósito deste artigo, a presença e a participação do Idac e da pedagogia freiriana se restringiram aos anos 1970. O projeto das 150 horas foi o de maior peso político-pedagógico, uma vez que mostrou o quanto a pedagogia de Freire é vinculada a sujeitos coletivos não só comprometidos com a transformação político cultural, mas também protagonistas dela.

\section{FREIRE E O DIÁLOGO COM OUTRAS EXPERIÊNCIAS E AUTORES DE PROPOSTAS EMANCIPATÓRIAS}

A Itália mais do que em outros países europeus, durante os anos 1960 e 1970, foi palco de experiências educativas muito significativas, portadoras de valores emancipatórios. Seus protagonistas - Aldo Capitini ${ }^{23}$, Dom Lorenzo Milani, ${ }^{24}$ Danilo Dolci ${ }^{25}$ e Mario Lodi ${ }^{26}$ - foram contemporâneos a Freire, produzindo trabalhos teóricos e desenvolvendo experiências em convergência com as obras de Freire daquele período ${ }^{27}$.

Os aspectos convergentes, que os aproximam dizem respeito aos seguintes princípios teórico-práticos: (1) o tema da comunicação e do diálogo; (2) a problematização de situações e de condições da vida quotidiana com a intenção de promover a conscientização de pessoas e grupos; (3) a pesquisa; (4) a reflexão; (5) o enfrentamento coletivo e cooperativo. Embora com ênfases e aproximações diferenciadas, o elo comum entre estes autores e Freire foi o de ter explicitado a relação entre educação e política no sentido atribuído por Freire: a não neutralidade dos objetivos e dos conteúdos educativos e a importância das práxis coletivas para a transformação de homens e mulheres em sujeitos ativos do processo de transformação do mundo.
22. VITTORIA, Paolo. Paulo Freire... Op. cit., p. 6-7.

23. Aldo Capitini (1899-1968) comprometido com o movimento da não violência promoveu em Perugia, no segundo pós-guerra, a experiência dos Centros de Orientação Social, espaços de autoeducação e de democracia direta. Foi animador da marcha pela paz Perugia-Assis e docente de pedagogia nas universidades de Cagliari e Perugia.

24. Don Lorenzo Milani (1923-1967) foi ordenado sacerdote em 1947 e enviado a San Donato di Calenzano, em Florença, onde fundou uma escola popular para jovens operários e camponeses. Em 1954, foi nomeado pároco de Sant'Andrea a Barbiana, uma pequena vila de Montagnana. No ano seguinte, construiu uma escola para os jovens do povoado que haviam concluído a escola primária. Nesta escola popular, aberta a jovens e adultos de todas as classes sociais, gerenciada com autonomia, organizada a partir das características da comunidade local e baseada nos princípios da aprendizagem mútua e circular entre educador e educando, tinha como objetivo e núcleo curricular o ensino da língua italiana, requisito fundamental para superar o analfabetismo e criar condições para a participação ativa dos indivíduos na vida social e política. O projeto educativo tinha entre suas principais características: os conteúdos desenvolvidos a partir dos problemas do cotidiano e da realidade dos alunos; o diálogo entre professor e aluno; o princípio da troca de saberes - peer education -; a orientação colaborativa; a aprendizagem recíproca; a adequação do funcionamento escolar ao tempo e ao ritmo de trabalho dos camponeses; a veiculação da valorização da cultura e dos modos de vida popular, bem como de valores ético-religiosos e não consumistas. Depois da publicação do livro Lettera a una professoressa, em 1967, 


\section{comunicação \& educação • Ano XXVI • número 2 • jul/dez 2021}

traduzido para o português como Carta a uma professora: pelos rapazes da escola de Barbiana, em 1975, esta escola se tornou uma espécie de símbolo da denúncia da segregação e das injustiças perpetuadas pela escola tradicional e elitista italiana daquele período.

25. Danilo Dolci (1924-1997) fundou, em 1958, em Partinico, província de Palermo, um centro de atividades socioeducativas em um contexto socioeconômico e político desagregado devido à tragédia da Segunda Guerra Mundial. A obra de Danilo Dolci começa em 1952, no extremo oeste da Sicília, que era habitado, sobretudo, por pessoas que viviam em condições de degradação econômica e política, culturalmente submersas ou controladas pela máfia. Durante a sua atividade na Sicília, a sua ação educativa e emancipatória contribuiu para o desenvolvimento social e cultural das classes desfavorecidas, utilizando uma metodologia de educação para a paz, para o diálogo e para a luta não violenta.

26. Mario Lodi (1922-2014) foi professor, pedagogo e escritor. Iniciou a sua trajetória profissional como professor primário, em 1948, quando descobriu as habilidades criativas das crianças e a sua importância para uma metodologia adequada. Ao entrar em contato com a pedagogia de Célestin Freinet, descobre alternativas para o trabalho na escola tradicional e nocionística da época e passa a adotar em sua prática cotidiana o texto livre, o cálculo vivo, atividades expressivas-pintura, teatro, dança etc. -, pesquisas de campo, correspondências interescolares, impressões escolares e a escrita individual de contos e livros. Ao mesmo tempo, dedicou-se a atividades extracurriculares, como a Biblioteca

Popular da Cooperativa de Consumo. Em 1957, no âmbito da biblioteca, criou - Grupo Padano para pesquisar documentos relativos
Diante disso, teria havido algum tipo de intercâmbio epistolar, diálogo e/ ou troca de experiências entre eles e Freire?

As obras e pesquisas consultadas para este trabalho estabelecem ligações conceituais e operacionais nítidas entre as propostas e as práticas de Freire e alguns dos autores mencionados. Alguns estudos relatam situações de intercâmbio entre Freire e Danilo Dolci e Mario Lodi.

Quanto ao primeiro, em pesquisa recente, Benelli e Schachter ${ }^{28}$ assinalam uma colaboração entre Dolci e Freire. Tal colaboração foi descrita por Danilo Dolci em seus escritos Quem sabe se os peixes choram: documentação de uma experiência educacional, de 1963, O que aprendi e outros escritos, de 2008, e Da transmissão à comunicação, de 1988. Nesses textos, há indícios de um diálogo circular entre Freire e Dolci em seminários em que, de forma participativa, discutiram possíveis métodos e ferramentas participativas, dialógicas e de valorização das minorias e sua utilização em diferentes contextos. Para além das questões pedagógicas, os dois autores também teriam desenvolvido propostas metodológicas para promover a participação ativa e cidadã.

Quanto a Mario Lodi, as poucas referências encontradas dizem respeito a uma possível participação de Lodi como expositor na mesma mesa de debates de Freire em uma conferência nacional do Centro de Educação Mundial (CEM), em julho de 1986. Observa-se pela leitura das obras de ambos os pedagogos que a sintonia entre eles parece resultar de determinados pontos de intersecção entre suas pedagogias: ambas valorizam e praticam a educação popular dentro e fora da escola e se preocupam em fazer do ambiente escolar um espaço de construção de saberes e conhecimentos vivos, atuais e de inclusão da cultura popular. Em outras palavras, tanto Paulo Freire quanto Mario Lodi investiram na construção de propostas para a edificação de uma escola popular e cidadã.

\section{A REDESCOBERTA DAS OBRAS DE FREIRE A PARTIR DOS ANOS 2000}

No final dos anos 1970 e durante as décadas de 1980 e 1990, com o advento dos processos de globalização da economia, das novas tecnologias de comunicação e informação e com a difusão das concepções do neoliberalismo, a pedagogia freiriana deixa de ser uma referência político-pedagógica de grande impacto na Itália. A pedagogia freiriana ficou saudosamente circunscrita às experiências e às propostas de alfabetização de adultos, sendo suas obras posteriores pouco ou nada conhecidas. Tais obras circulavam apenas entre alguns grupos vinculados aos movimentos progressistas da Igreja Católica e em grupos de pesquisa envolvidos em debates sobre a educação de adultos, reconhecidos no âmbito didático-metodológico por sua afinidade com os métodos autobiográficos e narrativos, como assinala Novara ${ }^{29}$.

Freire continuou, contudo, sendo mencionado e fazendo parte de alguns programas universitários nos departamentos de pedagogia social da Universidade 
de Roma e da Universidade de Bolonha, esta última sendo, durante os anos 1980 e 1990, guardiã das obras freirianas junto com a Universidade Salesiana de Roma. Na Universidade de Bologna, em janeiro de 1989, foi conferido a Freire o título de honoris causa em Pedagogia. Os professores Bartolomeo Bellanova ${ }^{30}$, docente de Pedagogia Social na Faculdade de "Scienze dela Formazione", Fausto Telleri ${ }^{31}$, docente de ensino geral na Universidade de Bolonha, e Carlo Nanni ${ }^{32}$, da Universidade Salesiana de Roma, foram responsáveis pela divulgação das primeiras obras de Freire, pois mantinham contato com o educador e com outros intelectuais que vieram a criar o Instituto Paulo Freire de São Paulo, em 1992, por vontade do próprio Freire ${ }^{33}$.

Em 2000, Telleri e Bellanova foram responsáveis pela organização e a hospedagem do II Fórum Internacional Paulo Freire. O fórum, que foi sediado na Universidade de Bolonha, era uma iniciativa que fazia parte das ações desenvolvidas pela rede internacional dos institutos freirianos e da Universitas Paulo Freire (UniFreire), como veremos adiante. Foi durante o fórum que surgiu a ideia de se criar um instituto italiano.

\section{A CRIAÇÃO DO INSTITUTO PAULO FREIRE ITALIANO}

Os contatos do IPF-SP com os professores da Universidade de Bolonha no final da década de 1990 e início dos anos 2000 lançaram as primeiras sementes para a criação do instituto italiano, ideia retomada durante o II Fórum Internacional de Paulo Freire. Na época, os professores Bellanova e Telleri já haviam sido convidados para fazer parte do Conselho Internacional dos IPF. Após o II Fórum, a proposta ganha a anuência e o apoio de outros docentes e intelectuais italianos e, em 2005, cria-se oficialmente o IPF Itália, tendo como sede Milão. Telleri, Bellanova e Nanni integraram o quadro dos sócios fundadores, acrescido de outros pedagogos e professores universitários.

O IPF Itália foi criado como uma associação de promoção cultural com os objetivos de: (1) promover atividades culturais e de formação, atualizando, reinventando e promovendo a contribuição pedagógica e cultural de Paulo Freire, além de adaptá-la ao contexto sociocultural italiano visando, assim, à promoção humana e à educação crítica e emancipatória; (2) contribuir para o debate cultural e científico sobre as questões do trabalho educativo e social no desenvolvimento das comunidades, dedicando especial atenção à superação das distâncias entre as diferentes entidades científicas ou institucionais, como universidades, instituições educacionais, organizações sem fins lucrativos e empresas em perspectiva de intercambiar e integrar perspectivas culturais a seu cotidiano; (3) contribuir para o desenvolvimento da educação de adultos e para a formação de um trabalho comunitário na realidade italiana por meio de intervenções de caráter experimental e inovador; (4) alimentar a trajetória de crescimento cultural e profissional de jovens educadores sociais e comunitários, professores, animadores e formadores das áreas de educação, saúde e serviço às expressões, canções e bonecos populares. Pode-se dizer que Lodi difundiu a cultura e as diversas formas de educação popular dentro e fora da escola oficial. Em 22 anos de ensino, produziu muitos livros, tanto de contos escritos em conjunto com os seus alunos quanto outros que documentaram as suas experiências de inovação e pesquisa dentro e fora da escola. Em 1989, fundou a Casa das Artes e do Jogo, um laboratório experimental de utilização de formas de linguagem humanas. No mesmo local, criou um centro de estudos e pesquisa sobre a cultura da criança e as novas linguagens multimídia e uma galeria de arte sobre as fases do desenvolvimento infantil. Publica, ainda, 67 cartilhas de contos de fadas e poemas infantis que expressam atitudes e sentimentos positivos - comunicação, colaboração, respeito à natureza e aos homens, felicidade etc. - e temas ligados à educação ambiental. Dedica-se, também, à educação orientada para a cidadania democrática e realiza oficinas para crianças, professores e educadores. Em 2001, começa uma experiência de troca de escritos autobiográficos com crianças. Mario Lodi foi autor de mais de 50 publicações nas áreas da comunicação escrita e artes e foi coautor com outros especialistas, bem como com crianças e adolescentes.

27. REGGIO, Piergiorgio. Reinventare... Op. cit., p. 33

28. BENELLI, Caterina; SCHACHTER, Christel. Paulo Freire e Danilo Dolci: connessioni metodologiche. In: ELLERANI, Piergiuseppe; RIA, Demetrio (ed.). Paulo Freire pedagogista di comunità: libertà e democrazia in divenire. Puglia: Università del Salento, 2017. p. 193-204.

29. NOVARA, Daniele. II metodo di Paulo Freire in Italia. In: TELLERI, Fausto (org.). Il metodo Paulo Freire: nuove tecnologie e sviluppo sostenibile. Bologna: Clueb, 2000. p. 85. 


\section{comunicação \& educação • Ano XXVI • número 2 • jul/dez 2021}

30. BELLANOVA, Bartolomeo. Introduzione ao livro. In: TELLERI, Fausto (org.) II metodo Paulo Freire: nuove tecnologie e sviluppo sostenibile. Bologna: Clueb, 2000

31. TELLERI, Fausto (org.) Il metodo Paulo Freire nuove tecnologie e sviluppo sostenibile. Bologna: Clueb, 2000

32. NANNI, Carlo. Teoria... Op. cit., p. 96

33. Ibidem

34. MAFRA, Jason. Apresentação da Unifreire. In: TORRES, Carlos Alberto et al. Reinventando Paulo Freire no século 21. São Paulo: Editora e Livraria Instituto Paulo Freire, 2008 p. 9-40. social; (5) participar no debate e na experimentação a fim de desenvolver a integração europeia em matéria social e de formação, criando parcerias com outros países membros da União Europeia (UE); (6) participar e colaborar com a rede internacional de IPF e a UniFreire.

Desde sua fundação, o IPF Itália tem sido promotor de muitas atividades: conferências, encontros, seminários e cursos breves voltados para estudantes, educadores das áreas socioculturais e educativas, professores e pesquisadores. Além disso, deu continuidade à tradução de importantes obras do pensamento freiriano, como a reedição dos livros Pedagogia do oprimido, Pedagogia da esperança e Pedagogia da autonomia. O IPF Itália é participante ativo dos fóruns internacionais Paulo Freire, que se realizam em intervalos de dois anos, e faz parte da rede e do conselho dos institutos feriríamos no mundo, que atualmente constitui uma rede internacional ${ }^{34}$.

Em 2014, o IPF Itália patrocinou o IX Fórum Internacional em Turim, Piemonte, entre 17 e 20 de setembro, com o título Sentieri di emancipazione al di là della crisi: temi generatori del pensiero educativo e sociale di Paulo Freire.

O fórum foi organizado pelo IPF italiano e o Grupo Abele, em colaboração com os IPF mundiais e com a participação especial da UniFreire e do IPF de São Paulo. A preparação do fórum foi precedida de reuniões realizadas nas diversas sedes locais do instituto para a discussão do documento elaborado pela comissão científica - organização e programação do evento, objetivos, divulgação e formas de garantir um maior envolvimento e participação das entidades nacionais e internacionais. $\mathrm{O}$ objetivo do evento era contemplar momentos de análise e de novas contribuições por meio de conferências, amostras e trocas de experiências nos círculos de cultura.

O programa do fórum incluiu os principais temas geradores do pensamento de Paulo Freire. Eles foram posteriormente utilizados na construção de projetos e experiências no campo da docência, da educação informal, em projetos de desenvolvimento social e comunitário e no campo da saúde e das políticas públicas.

Os temas foram desenvolvidos em dois eventos integrados e consecutivos. O primeiro evento abordou os seguintes temas: pedagogia freiriana em um mundo globalizado; educar para capacitar desigualdades e vulnerabilidades; lidar com problemas locais, estimulando a participação do cidadão; desenvolver a consciência ecopedagógica e a cidadania planetária; educar e emancipar a arte da comunicação existencial; construir espaços de justiça em territórios marcados pela corrupção e ilegalidade.

O segundo evento foi orientado para o diálogo e a troca de boas práticas, valorizando as experiências concretas que remetem à pedagogia freiriana nos diversos espaços educativos - formais e informais - do mundo socioeducativo. Se no primeiro evento os temas foram desenvolvidos de forma teórico-prática, nas rodas do segundo foi dado maior destaque ao intercâmbio e ao debate de práticas.

O fórum teve 290 inscrições e 77 relatores, provenientes de várias regiões da Itália, de outros oito países da comunidade europeia e de 11 países fora 
da UE. Os participantes pertenciam a diversos tipos de entidades, como associações, cooperativas, organizações não governamentais (ONG) nacionais e internacionais e universidades.

Como se pode verificar não só pelo número de participantes, mas também pelos organismos nacionais e internacionais que participaram no fórum, a iniciativa teve grande sucesso, tanto em termos de audiência como na qualidade dos trabalhos apresentados. Além das conferências, que exploraram questões relacionadas à globalização e aos processos de vulnerabilidade e exclusão ligados ao mundo e à realidade italiana, foram tratados temas e problemas relacionados à exploração dos recursos do planeta, à luta pelos direitos das minorias, ao acesso à educação e à superação dos modelos educacionais "bancários". No que toca às respostas alternativas, como a possibilidade de sinergia para superar e transformar as condições de desvantagem e exclusão, foram apresentados muitos projetos, práticas e experiências realizadas nos diversos países e regiões italianas que enfocavam o reconhecimento do saber popular, a participação a partir das bases, o desenvolvimento de uma consciência crítica em nível planetário e a importância das práticas educacionais formais e informais, culturais e políticas. Tais práticas e iniciativas têm enfoque comuns: elas privilegiam o diálogo crítico, o reconhecimento da importância da memória coletiva, a cooperação, a solidariedade e a necessidade de construir bens comuns. Neste contexto, foram apresentadas cerca de 120 intervenções agrupadas nos temas do primeiro evento.

A comparação e a interação entre propostas e experiências nos círculos culturais foi intensa e contínua durante os dias do Fórum, possibilitando a abertura de novas oportunidades de intercâmbio entre participantes locais e estrangeiros.

Entre os palestrantes convidados para as conferências, além dos mais renomados professores e pesquisadores da pedagogia freiriana, estava a famosa filósofa húngara Ágnes Heller, que fechou o evento ao lado de Dom Luigi Ciotti e Moacir Gadotti, este último um famoso filósofo brasileiro da educação e fundador, junto com Paulo Freire, do IPF de São Paulo.

Após a realização do IX Fórum, outras atividades pontuais foram promovidas; contudo, não com a mesma intensidade do período anterior. Foram várias as razões externas, conjunturais e organizativas internas, próprias de uma associação que enfrenta o desafio de incluir as novas gerações de educadores, estes imersos em um mundo globalizado cuja supremacia é detida pelas mídias e pela internet, que influenciaram o alcance dos eventos posteriores ao fórum.

Atualmente, em 2021, o IPF Itália está se reorganizando para fazer frente aos novos contextos tecnológicos do campo da informação, bem como para enfrentar os novos problemas e desafios gerados por quase dois anos da pandemia da covid-19.

Se o mundo globalizado tem sido palco de transformações muitas vezes traumáticas, submetendo pessoas e povos a novas formas de opressão, expropriação de culturas e recursos, a pandemia recrudesceu e criou novas desigualdades, 
por exemplo, aumentou os índices de pobreza, devido à elevada taxa de desemprego, diminuiu a renda e eliminou serviços essenciais básicos. Aos vários efeitos crônicos pré-pandêmicos, somam-se novos desafios: o incremento do analfabetismo funcional de adultos e adolescentes - evadidos da escola -, a exclusão digital, a descontinuidade e perda de qualidade dos serviços educacionais, o aumento dos índices de evasão e reprovação escolar e os problemas de natureza psicofísica - isolamento, depressão, medo, insegurança em relação ao futuro etc. - que atingem diversas faixas etárias.

A busca por maior justiça social, democracia e humanização, assim como o combate à degradação do planeta e a luta pela superação das lógicas perversas instauradas pelo modelo neoliberal e suas ramificações na educação, no meio ambiente, na cultura e na política, vem se renovando e tomando iniciativas, ainda que pontuais, para superar estes problemas.

Outrossim, tais iniciativas também envolvem a procura de novos referenciais e parâmetros epistemológicos e político-educativos. Renasce, portanto, o interesse dos mais jovens pelas obras e pelo pensamento de Paulo Freire em diversos espaços sociais e culturais. A construção de um mundo em que todos, individual e coletivamente, tenham a possibilidade de serem mais $^{35}$, como escreveu Paulo Freire, continua sendo um farol, em direção ao futuro.

Nesse caminho de navegação para o futuro, o IPF Itália se agrega às iniciativas que podem reinventar e recriar o legado de Freire, quer seja para a construção de projetos e ações coletivas emancipatórias de intervenção em diversos âmbitos - socioeducativos, culturais, de mídia, profissionais, políticos e ambientais -, quer seja na elaboração de referenciais teórico-epistemológicos de modelos críticos de educação e cultura que se aderem à realidade.

\section{REFERÊNCIAS BIBLIOGRÁFICAS}

BELLANOVA, Bartolomeo. Introduzione ao livro. In: TELLERI, Fausto (org.). Il metodo Paulo Freire: nuove tecnologie e sviluppo sostenibile. Bologna: Clueb, 2000.

BELLANOVA, Bartolomeo. Paulo Freire: educazione problematizzante e prassi sociale per la liberazione - contesti antologici di e sull'autore appendice su documenti ed esperienze. San Prospero: Modena, 1978.

35. Expressão cunhada por Freire que expressa a vocação de humanização característica dos seres humanos na busca de justiça, liberdade e autonomia. Pode ser encontrada em vários de seus livros - Pedagogia da autonomia, Pedagogia da esperança etc
BENELLI, Caterina; SCHACHTER, Christel. Paulo Freire e Danilo Dolci: connessioni metodologiche. In: ELLERANI, Piergiuseppe; RIA, Demetrio (ed.). Paulo Freire pedagogista di comunità: libertà e democrazia in divenire. Puglia: Università del Salento, 2017. p. 193-204.

FREIRE, Paulo; ROSISKA, Miguel; OLIVEIRA, Darcy de; CECCON, Claudius. Vivendo e aprendendo: experiências do Idac em educação popular. 4. ed. São Paulo: Brasiliense, 1981. 
GADOTTI, Moacir. The global impact of Freire's pedagogy. New Directions of Evaluation, London, v. 2017, n. 155, p. 17-30, 2017.

MAFRA, Jason. Apresentação da Unifreire. In: TORRES, Carlos Alberto et al. Reinventando Paulo Freire no século 21. São Paulo: Editora e Livraria Instituto Paulo Freire, 2008. p. 9-40.

MANFREDI, Silvia Maria. Educação profissional no Brasil: atores e cenários ao longo da história. Jundiaí: Paco, 2016.

NANNI,Carlo. Teoria e metodo Freire in Italia. In: INTERNATIONAL FORUM PAULO FREIRE, 2., 2002, Bologna. Anais [...]. Bologna :Clueb, 2002.

NOVARA, Daniele. Il metodo di Paulo Freire in Italia. In: TELLERI, Fausto (org.). Il metodo Paulo Freire: nuove tecnologie e sviluppo sostenibile. Bologna: Clueb, 2000.

REGGIO, Piergiorgio. Reinventare Freire: lavorare nel sociale con i temi generatori. Milano: Franco Angeli, 2017.

TELLERI, Fausto (org.). Il metodo Paulo Freire: nuove tecnologie e sviluppo sostenibile. Bologna: Clueb, 2000.

VITTORIA, Paolo. Paulo Freire e l'educazione degli operai in Italia. Alternative - rivista per il socialismo, Roma, p. 1-10, 2007. 